\title{
Peer mentorship and transformational learning: PhD student experiences
}

\author{
Jane P. Preston \\ University of Prince Edward Island \\ Marcella J. Ogenchuk \\ University of Saskatchewan \\ Joseph K. Nsiah \\ Catholic Secretariat, Jasikan, Ghana
}

\begin{abstract}
The purpose of the paper is to describe our peer mentorship experiences and explain how these experiences fostered transformational learning during our $\mathrm{PhD}$ graduate program in educational administration. As a literature backdrop, we discuss characteristics of traditional forms of mentorship and depict how our experiences of peer mentorship was unique. Through narrative inquiry, we present personal data and apply concepts of transformational learning theory to analyze our experiences. Our key finding was that it was the ambiguous boundaries combined with the formal structure of our graduate program that created an environment where peer mentorship thrived. We conclude that peer mentorship has great capacity to foster human and social capital within graduate programs for both local and international students.
\end{abstract}

\section{Résumé}

Le but de cet article est de décrire nos expériences de mentorat par les pairs et d'expliquer comment ces expériences ont favorisé l'apprentissage transformationnel au cours de notre programme d'études supérieures de doctorat. Avec la littérature comme toile de fond, nous discutons des caractéristiques des formes traditionnelles de mentorat et décrivons comment notre mentorat par les pairs est unique. Grâce à l'analyse narrative, nous 
présentons des données personnelles et appliquons les concepts de la théorie del'apprentissage transformationnel pour analyser nos expériences. L'élément clé de l'étude démontre clairement que les frontières ambiguës, combinées à la structure formelle de notre programme d'études supérieures, créent un environnement favorable au mentorat par les pairs. À la lumière de notre étude, nous concluons que, tant pour les étudiants locaux qu'internationaux, le mentorat par les pairs rehausse le développement humain et social dans les programmes d'études supérieures.

Canadian higher education is in the midst of significant transformation, and, within the next decade, most postsecondary institutions will emerge from these tumultuous times distinctively different (Black, 2010). This flurry of change is reforming the cultural norms of universities, subjecting educational leaders and instructors to higher levels of financial transparency, increasing demands for student choice in the delivery and content of classes, and increasing pressure to document quality teaching evaluations and professional impact factors. Amid this market-focused milieu, instructors grapple with intensified competition for research funding, higher requirements for publications, larger class sizes, and larger numbers of graduate students to supervise. Alongside pressures to promote efficiency, effectiveness, and economic competitiveness (Skelton, 2005), instructional leaders are committing to student expansion, a tactical strategy within the competitive educational landscape. In an attempt to function and thrive within this challenging setting, what supports do university leaders and instructors have available to them to promote student success?

Addressing the above question, we recognize peer mentorship as an untapped, practical, economical, and effective source in fostering student achievement within university settings and, more specifically, within $\mathrm{PhD}$ graduate programs. Focusing on peer mentorship and transformational learning, we describe our peer mentorship experiences and explain how these experiences promoted transformational learning during our $\mathrm{PhD}$ graduate program in educational administration. As a background to our stories, we discuss characteristics associated with traditional forms of mentorship and present our unique definition of peer mentorship. We use qualitative features of narrative inquiry to present personal data and apply concepts of transformational learning theory (Mezirow, 1981, 1991, 1997, 2000; Mezirow, Taylor, \& Associates, 2009) to analyze our experiences. From these self-reflections, we conclude that it was both the ambiguous boundaries and transparent structure of our graduate program that created an environment where peer mentorship thrived. We propose a number of implications arising from incorporating peer mentorship into higher education.

\section{Depictions of Traditional Mentorship and Peer Mentorship}

Trorey and Blamires' (2006) portrayal of mentorship is that of an older and wiser individual influencing the intellectual and professional development of a younger protégé. Similarly, Auger and Rich (2007) stated, "Mentorship occurs when a role model offers support to another person and shares knowledge, expertise, and experiences with that person" (p. 394). Many authors recognize that mentorship has myriad personal, profes- 
sional, and organizational benefits (Allen \& Eby, 2007; Fresko \& Wertheim, 2003), and, in such cases, mentoring is typically referred to and approached as a hierarchical relationship between two people. Under this dyadic portrayal, common synonyms for mentors are teacher, tutor, coach, counsellor, consultant, advisor, and professional guide.

Juxtaposed with the traditional concept of mentorship is the notion of peer mentorship. Some researchers depict peer mentorship as a best practice for fostering student learning (e.g., Badger, 2010; Grant-Vallone \& Ensher, 2000; Huizing, 2012; Kincaid \& Sotiriou, 2004). In such situations, students are recognized as the holders of experiential and intellectual knowledge; consequently, they are authentic teachers for fellow peers (Le Cornu, 2005). As Heirdsfield, Walker, Walsh, and Wilss (2008) noted, there is growing evidence about the need for programs where beginner students receive support from senior university students, rather than from faculty and academic staff.

We build upon Heirdsfield et al.'s (2008) idea and advocate the benefits of having beginning students receive support from fellow beginning students. As a feature of our unique research, peer mentorship involved a cohort of $\mathrm{PhD}$ students who thrived in a caring and cooperative learning environment. For us, peer mentorship was a natural process where collegial friends (a cohort) shared an academic journey and supported each other intellectually, physically, emotionally, and spiritually. In our case, peer mentorship took place among a group of students who shared their knowledge, experiences, and support in a trustful environment, thereby enhancing the individual and collective learning of the group.

\section{Research Methodology and Analytical Framework}

Below, we describe the research method chosen to collect the data and the conceptual framework used to analyze the data. More specifically, narrative inquiry provided a medium for data collection via self-reflection, and transformational learning theory added philosophical value to our personal stories.

\section{Narrative Inquiry: Data Collection and Analysis}

Narrative inquiry has assisted researchers in understanding the nuances of teacher education, educational practices, and educational experiences (Craig, 2011). To help gain insight into the complexity of educational practices, narrative inquiry in various studies originally documented stories about Kindergarten to Grade 12 teaching experiences. Within these stories, teachers shared personal and professional challenges and offered unique, lived solutions to teaching obstacles (Clandinin, 2006; Clandinin \& Connelly, 1998, 2004). The collection of these data involved teachers (as research participants), communicating past experiences, successes, challenges, and solutions. By reflecting on "personal professional knowledge," teachers became empowered and began to teach with more constructive foresight (Connelly \& Clandinin, 1988, p. 25). "Because teachers' knowledge is found and lived in their narratives of experiences, narratives of experience are, then, educative (Ciuffetelli Parker, Pushor, \& Kitchen, 2011, p. 7). Through narrative inquiry, reflection and learning become directly proportional-the more reflection, the more learning (Dewey, 1938). Arising from this philosophical grounding, a nascent realm of research has expanded to include an array of vocational contexts and is now used to collect data about any potential significant or transformational event (Chase, 2005). 
Herein, we use narrative inquiry to explain how peer mentorship fostered transformational learning during our PhD graduate program. By using this research framework, we emphasize the significance of social interaction (Gill \& Goodson, 2011) and describe how our personal connections with the peers in our cohort supported our intellectual growth and overall wellbeing. An important aspect shared by narrative inquiry and our stories is that they exhibit a subjectivist epistemology, which endorses the idea that knowledge is filtered through the interpretations of individual people and, hence, is differentially defined (Schwandt, 2007).

The data collection and analysis for this research spanned over six months. During this time, data collection involved both informal and formal phases. The informal phase involved discussions between the three authors shortly before and after we defended our $\mathrm{PhD}$ dissertation. These nostalgic conversations took place while we socialized at coffee shops and frequented university events. The more formal phase of data collection commenced shortly after Jane Preston and Marcella Ogenchuk attended a conference entitled, "The Forum on Mentorship Across the Professions" (June 2010, Saskatoon). After this inspirational event, Preston and Ogenchuk decided to document their stories in a written format and invited Joseph Nsiah to do so, as well. Over the next month, we each wrote approximately 2,500 words explaining how peer mentorship influenced us during the $\mathrm{PhD}$ program. We shared these stories through email and a face-to-face meeting to analyze the data. During our data analysis, we identified the common themes surfacing from our stories, and we talked about the differentiated experiences of each of us. Due to length limitations, we cut the repetitive and superfluous details from our stories, and the results are found in this article.

\section{Transformational Learning Theory}

Transformational learning theory pertains to learning that is influenced by personally relevant experiences, which emerge through social interactions, peer dialogue, and selfreflection. Experiencing transformational learning involves acknowledging one's values, beliefs, and worldviews and critically assessing whether those fixed opinions are functional and true in all contexts. Before transformational learning can occur, a number of essential events need to happen. First, an individual needs to critically reflect on an experience, participate in safe but exposed dialogue about the experience, and learn from the views and experiences of others in an emotionally open way (Taylor, 1998, 2007, 2009). After such reflection, the person cross-examines assumptions and convictions deeply rooted within one's psyche. Transformational learning is more fully enabled when educators create a safe communicative learning environment, where students can openly discuss conflicting feelings, thoughts, and past actions (Carter, 2002; Taylor 1998, 2009). Through experiencing these stages of learning, a student acquires a contemporary, broader comprehension of life.

Mezirow (1997) pointed out that transformational learning often involves uncomfortable aspects of learning, which may include (a) disorientation and confusion, (b) self-examination of assumptions, (c) recognition that others are negotiating similar changes, (d) exploration of new relationships, new roles, and a plan of action, (e) creation of self-confidence in new roles, and (f) integration of a new perspective into one's life (pp. 168-169). Mezirow described transformational learning as dichotomously exhilarating and chal- 
lenging. Mezirow added that this reflective-based learning develops "autonomous thinking" (p. 5), a practice where an individual is guided by personal interpretations, rather than idly following the perceptions, judgement, and feelings of family, friends, and teachers. The ultimate result of transformational learning is a state of personal emancipation, sometimes embodied through participation in social-action campaigns aimed at addressing social injustices (Brockett \& Hiemstra, 1991; King, 2005; Mezirow, 1981).

When participating in social justice campaigns, features of transformational learning align with the teachings of Paulo Freire (1970, 2004a, 2004b) and Henry Giroux (1981, $1983,1996)$. Although it is not our intent to delve into the intricacies Freire and Giroux's extensive work, reference to certain aspects of their writings complement features of transformational learning theory. For example, Friere's (1970) work highlighted the emancipatory nature of critical reflection and how reflective practices lead to the highest expression of one's potential. Giroux (1983) believed that the theory and practice of education should create critically thinking citizens who are enabled to positively transform society.

\section{Narrative Data with an Analytical Thread}

The following is a general overview of our $\mathrm{PhD}$ cohort followed by three personal narratives, each of which is trailed by an analytical thread outlining how transformative learning transpired due to peer mentorship.

\section{Our PhD Cohort}

Our group ranged in age from the late 20 s to mid-50s. Of the 10 students enrolled in the cohort, five individuals were male and five were female. In terms of homelands, we were an eclectic bunch, with representatives from Bangladesh, Canada, China, Finland, and Ghana. The majority of us conversed in a second or third language. In terms of professions, we had each been or were teachers, nurses, librarians, priests, and managers in various capacities. With such an internationally and professionally dynamic group, we regularly discussed a plethora of political, cultural, religious, and philosophical issues during our program. Ironically, the group's heterogeneity assisted in creating the group's homogeneity. That is, because the students in our cohort did not represent one dominant cultural voice or view, discussion involving issues such as left-right politics, ethics, socioeconomic status, religion, and sexuality (to name a few) were a well-balanced exchange of thoughts and perspectives. Paradoxically, our diversity was our strength.

\section{Jane Preston's Story}

Although committed to the academic challenge, a barrage of self-doubts and questions assaulted me during the beginning of my graduate program. What was I doing here? Was I really PhD worthy? Was the PhD journey one of selfishness? In contrast to these predominantly self-defeating thoughts, the professors within our department warmly welcomed us to the College of Education and sponsored Graduate Orientation Week and a student-professor luncheon at the campus faculty club. During these cheerful occasions, each new PhD student introduced him- or herself and their spouse or family member who were also welcome. Professors reciprocated with self-introductions; they identified the classes they taught, described their research interests, and discussed the possibility of 
co-conducting research. Although I had not officially started the program, I felt accepted, respected, and valued by my professors, therein relieving some of my initial fears.

Nonetheless, encouraging a new cohort of students to work with and trust each other requires more than an orientation and luncheon. Establishing a culture of peer mentorship would necessitate many relationship-building opportunities, and, attuned to this requirement, our professors provided continual support. For instance, in the middle of a three-hour morning class, one particular professor would give us a break and accompany us to the faculty lounge. During these times, we took turns bringing cake and joining in song as we celebrated student and professor birthdays and other special events such as Valentine's or St. Patrick's day. I looked forward to sharing this downtime (or perhaps uptime) with a group of people who were fast becoming my friends.

As we progressed through the courses, other instructors encouraged our cohort to connect academically and socially. One professor wove group assignments into two offcampus weekend retreats, and, to prepare for these classes, students were obliged to meet outside of class time. Sometimes these peer meetings frustrated me and forced me to think in ways in which I was not accustomed. For example, during one meeting, I became annoyed with a peer, whom I will call Jackie. (Other than the authors' names, all names used throughout the article are pseudonyms.) Jackie and I were required to talk politics and policy and devise a plan about how to improve student literacy. Early in the homework session, communicative and perceptual challenges began to emerge within our discussion. It was obvious that Jackie and I possessed polar opposite views in terms of politics and policy. Although this difference of opinions was exasperating, we needed to gain consensus in order to successfully complete this assignment. Ultimately, it took three homework sessions to arrive at a well-balanced, written document. Even though we were forced to think in ways that were uncomfortable, the process proved to be academically emancipatory for each of us.

In preparation for another assignment, another student, Zack, and I met to discuss our plans for completing our written task. We planned to meet in a small, private computer lab, devoted to graduate students and their research needs. As he walked into the room, he greeted me by asking how I was doing. I confessed that I was feeling overwhelmed and said, "I feel like I am on a sinking ship." He responded, "Yeah, me too. It's called the Titanic!" This occasion was the first time I had worked one-on-one with Zack, and I was surprized by both his demeanour and response. I thought Zack was a genius, a person not in the least intimated by the demands of the program. It was comforting and empowering to know that, in truth, my fellow classmate shared my similar feelings of inadequacy, self-doubt, and frustration.

Throughout our first year together, my fellow classmates became a circle of friends who provided me with many additional personal and professional growth opportunities. For example, I gained a personal appreciation for the Muslim experience of Ramadan by observing one of my peers abstain from food and liquids during daylight for a month. Alongside another peer, my husband, son, and I celebrated Chinese New Year and learned some words in Mandarin that we still remember today. In talking with my peers and through peer editing of each other's writing, I began to more fully understand different types of research methodologies and educational research topics. During class and group time, as I listened to my classmates' voice their thoughts about contentious is- 
sues, I learned to separate the issue from the person, because the person was my friend. The value of these relationships not only enhanced our individual and collective strength but also, in one case, the peer mentorship support we provided for one student stopped that student from dropping out of the program. Throughout the year, our cohort became a structure of reciprocal support, and I came to realize that peer mentorship was not just a few friends academically supporting each other. Rather, peer mentorship was the creation of trust-trust embedded in one-to-one, one-to-many, and many-to-one conversations and social and professional interactions.

Analytical Thread: From Past to Present. Mezirow (1991) stated that one of the most important aspects of adult learning is freedom from habitual ways of thinking and acting. Upon entering the PhD program, I carried many internal and external barriers with me (King, 2005), obstacles that initially obstructed transformative learning from occurring. Examples of these barriers included a discomfort with group work and intense family pressures to maintain specific cultural and political views. Due to the academic discourse I shared with my peers, the moral influence of my peers, and the trusting relationship I developed with them, I was able to create, accept, and recognize change within me. This change still empowers me today, because I now enjoy increased self-confidence when I voice my views during meetings and in my writing. Compared to when I started the program, I can debate issues surrounding education, politics, and policy by addressing the issue not the person with whom I speak. I now speak about social justice issues from a much more wide-ranging point of view, recognizing the grave complexity of world problems; however, I also understand now that "it is the relationship between [the] difficulty and [the] possibility of changing the world that poses the question of how important the role of awareness is" (Freire, 2004b, p. 15). Moreover, due to my educational experience shared with my peers, I no longer feel the need to be right, because I now doubt that any one right exists in isolation. Also, my philosophical views have altered; I am more civically active, and I am more vociferous about my views, in general. Compared to the start of my program, a broader array of educational topics and research methodologies interest and intrigue me. These life-changing examples would not have happened if it were not for the trusting relationships I experienced through peer mentorship.

Learning with and vicariously through my peers, made me realize how, in the past, I had played my part in nurturing my own type of pedagogy of the oppressed (Freire, 1970). Both as a student and through my own classroom teaching, I embodied the idea that "the teacher teaches and the students are taught; the teacher knows everything and the students know nothing" (Freire, 1970, p 59). In contrast, our peer assignments and conversations gave a place, space, and case to value the experiences and views of all the students in our cohort. From peer mentorship, I learned that each student houses a raft of rich knowledge, and, when personal insight is shared among trustworthy peers, transformational learning emerges. Through peer mentorship, our group was able to take highly theoretical learning concepts and apply them to the realities of our lived experiences (King, 2005). This high level of learning involved the unveiling of multidisciplinary perspectives pertaining to gender, class, sexuality, nationality, colonialism, race, ethnicity, and critical pedagogy in an effort to better understand an event (Giroux, 1996). In a shared aura of peer mentorship, speaking about these issues and learning from each other's personal experiences truly was a transformational event. 


\section{Marcella Ogenchuk's Story}

Although fuelled with an innate desire to learn, my decision to enter into the doctoral program in educational administration was the result of intense deliberation. Nervousness and doubt set in when I first stepped into the classroom and realized that my $\mathrm{PhD}$ dream was beginning to materialize; I started to wonder if I had the ability to fulfill the program requirements. I felt intimidated by my lack of experience in academia. Did I even know what was necessary to complete this journey? Maybe the admission process I went through was flawed?

My first warm recollection of officially entering the program was through a welcome email from one of our professors. Upon meeting this professor for the first time, he displayed a sincere interest about who I was and why I had decided to pursue a PhD. I walked away from the initial meeting feeling confident that I was where I needed to be. The personable and social aspect of our meeting took me by surprize since I was expecting a serious, even stressful atmosphere; instead, I left his office fortified with a sense of hope in the future and assurance that I had made the right decision to enter the program. As I look back, the sincerity that I felt from him during that first social interaction was the genesis of the professional trust that later fully developed between him, me, and the rest of my peers.

Planned orientations and regular social and academic gatherings were instrumental in nurturing and modelling the supportive culture of the department in which we were enrolled. With gratitude, I recall that faculty members were accessible and kept their office doors open. When I met professors in the hallway, they took the time to greet me; they asked me how I was and how my family were doing. Faculty members actually stopped by our offices to say hello and to inquire if we had questions or needed clarification about assignments. In general, the faculty members always seemed to be available to us, and I believe our cohort of students modelled this behaviour by making ourselves available for each other.

As our program progressed, each student's academic demands and home and employment situations began to add layers of stress to our lives. Receiving and giving support to each other in our cohort became a way to survive and thrive both in our programs and personal lives. Many of us experienced life-changing events: some students tragically lost family members or struggled with health challenges. During these difficult times, professors showed understanding and flexibility, while peers showed respect and support for each other through emails, attending religious ceremonies, and providing time to listen. We shared coping mechanisms with one another. Some members of the cohort were more adept at dealing with life-changing events by running, and they invited others to join them outside of class time. These healthy activities proved to be valuable coping models in which subgroups within our cohort became actively involved. The selfless acts of our peers provided much-needed support in other capacities, such as sharing meals, taking time to teach each other necessary skills, such as learning to drive or providing transportation to friends in need. These gestures of kindness permeated our PhD cohort. Upon reflection, I realized that over the course of our program each one of my cohort members provided me with something that I needed in order to complete the PhD journey. A lesson I learned through this experience was that life-changing events naturally happen to everyone. Such challenges cannot be avoided or postponed, but they can be borne while simultaneously succeeding in a doctoral program. 
The support that existed within my cohort allowed me to focus on my primary purpose, which was to learn more-an inner drive that had initially led me to the program. Trust was established through sincere actions, revealing that our cohort's interests were as much collective as they were individual. The professors in the department also modelled behaviours that the students in our group began to emulate. I feel fortunate to have had been a part of that peer mentorship culture, because it proved to be vital to the completion of my doctoral dissertation. The entire experience enriched my life, provided me with lasting friendships, and offered me a valued student-focused learning model I could use in my professional life.

Analytical Thread: From Past to Present. It is apparent to me that during my $\mathrm{PhD}$ journey, I experienced many if not all, of the learning phases discussed earlier. The rich personal and professional relationships that emerged through peer mentorship were integral in fostering my growth throughout my $\mathrm{PhD}$ program. Critical self-reflection began the moment that I decided I was going to enter into the program. Clark (1993) suggested that transformational learning imparts more far-reaching changes in the learner than any other kind of learning. The personal changes I experienced strengthened my confidence in my profession as a teacher and researcher, and in my personal life. By continually talking with my peers during class and while sitting in our offices, I was able to validate and interrogate previous personal beliefs. These social interactions assisted me in establishing my research goals and agenda. Other personal beliefs were challenged and changed and, ironically, by far the most memorable moment was similar to Jane Preston's: the ability to more fully understand and accept others' views. This realization is paramount and has provided new meaning in my life. These changes have occurred from immersing myself in numerous rich discussions with a cohort of peers who presented views from various sociocultural, socioeconomic, and international perspectives.

Although, at times, these transformational recognitions were difficult and challenging to endure, the experience showed me how to become more accepting and productive within a pluralistic society. Through my peers and their mentorship influence, I learned how to construct, negotiate, and attach multiple meanings to any one reality. I came to understand aspects pertaining to hegemony, "[an] ideology that defines the limits of discourse in a society by positing specific ideas and social relationships as natural, permanent, rational, and universal" (Giroux, 1983, p, 409). More importantly, I learned how hegemony can prevent transformational learning and repress a society, because class, power, and dominant culture can devalue the need to attend to social justice issues. I learned that the transformational change I want to see in the world starts within me.

\section{Joseph Nsiah's Story}

At the start of the program, I was excited and optimistic about my academic future; however, this initial enthusiasm was soon transformed into nervousness and insomnia. A multitude of reasons accounted for this anxiety, but the main cause was best captured by the nagging question, "What is your dissertation topic?" My restlessness worsened when, early in the program, professors stressed the need to define and refine our research topics. As my classmates confidently and excitedly talked about how they planned to approach their research, my angst increased. I began to ask myself whether I had made the right choice enrolling in a PhD program. Fortunately, this restlessness started to abate, as my 
peers made time to listen to me and discussed my tentative research plans with me. During such interactions, I realized that my peers needed my input to clarify their research topics as much as I needed theirs. Equipped with a handful of vague ideas co-generated during peer discussions, I made appointments with several professors. It was during one such meeting that my research agenda finally became lucid.

Repeatedly throughout our time together, our group of 10 classmates embodied the adage "united we stand, divided we fall." The knowledge that we gave each other not only benefitted the recipient, but also the dispenser. Our dissemination of thoughts and ideas was supported by the close proximity of our shared office space. Some of us shared a oneroom office that contained three or four desks; others from our cohort were one or two doors down the hallway. This convenience of location permitted easy access to each other when we had course-based questions, borrowed or loaned materials, or sought clarification on assignments. Our willingness to share knowledge, resources, and talent were epitomized during various group-work tasks and when we provided editorial comments on each other's papers. Some students with subject-specific expertise (e.g., conducting an effective library search) presented workshops to our entire cohort. On our own time, the students within our cohort met to practise PowerPoint presentations for pending comprehensive examinations, conferences, or job interviews. Presenting information in front of peers was much less intimidating than facing a group of professors or an external audience. Peer mentorship proved to be a mutual and collaborative exchange of time, attention, and energy, benefitting all of us.

Looking back at my $\mathrm{PhD}$ experience, I give credit to my peers for teaching me most of the computer skills I have today. Entering the program, I estimate that it took me four to five times longer than my classmates to access online information and to complete assignments using a computer. Cognizant of the fact that my existence in the $\mathrm{PhD}$ program was contingent on computer skills, I asked my peers for help. My peers taught me how to navigate Microsoft Word, Publisher, and PowerPoint, how to create a table of contents, how to create tables and figures, and how to format documents using computer shortcuts. From their patience and direction, I gradually gained these technical skills, and I was able to type my dissertation without hiring the services of a professional typist. This accomplishment would not have been possible had I not been a recipient of peer mentorship.

Then, at the mid-point of my program as I was finally becoming somewhat comfortable being a PhD student, I faced a mandatory course I nicknamed "Almighty Statistics." The stakes were high-I needed to pass this course or I would be kicked out. Having to complete this course meant revisiting and reliving the mathematical humiliation I experienced throughout elementary and high school. The truth was, I was mathematically illiterate! Once again, I asked my classmates for help. One peer provided me with the typed notes he created after every class; several other peers provided me with moral support. In addition, to complete our assignments, I regularly met with our cohort-initiated stats homework group. It seemed so strange that with all this support, I still did not understand many of the concepts taught in the statistics class.

One day in discussing my statistics frustrations with one particular classmate, I said, "Dorothy, before you stands the most obtuse mind you will find when it comes to manipulating numbers. If you discuss statistics, consider me not only as tabula rasa but as a Grade 1 student." From that day forward, Dorothy dedicated approximately three hours 
a week to reteaching the course content to me in a one-on-one context. Like clockwork, every week, we made our way to an empty classroom, and, on the chalkboard, we worked through problem after problem after problem. In her spare time, she created homework assignments, mock midterm quizzes, and a mock final exam for me. I completed the assignments on my own, and she corrected them and returned them to me. Together we discussed and corrected my mistakes. Her aptitude for simplifying concepts that to me were so intricate and complicated, soothed my fears about numbers and this high-stakes class. Thanks to the efforts of Dorothy and my peers, I passed the statistics course. I was thrilled when Dorothy told me that she believed she developed a better understanding of statistics because of the time we spent together.

Analytical Thread: From Past to Present. Transformational learning is about change and improving the way we view ourselves and the world (Merriam, Caffarella, \& Baumgartner 2007). Interacting with my colleagues and being open to new ideas taught me that things that an individual considers impossible are possible when he or she is willing to share and receive help. How could I have passed statistics, which I was predisposed to fail, if it was not for the assistance of my peers? I learned that relationships devoid of complacency and fear lead to personal and professional growth (Freire, 1970). My experiences of peer mentorship revealed to me that having a common course of action (e.g., being enrolled in a $\mathrm{PhD}$ program) has great potential to harmonize race, gender, religion, and subtle differences, thus transforming them into a collaborative force of success. Adult learning, cemented in relationships, collaboration, and friendships taught me that with a critical and reflective attitude, long-held personal beliefs can change. For example, some of the paralyzing worldviews I held concerning Western individualism led me to form inaccurate conclusions about a culture that initially I did not understand. In spending time with my friends and being immersed in their culture was a truly transformational experience. I learned to think outside the box, because a single confined box cannot contain all there is to know. Through my PhD peer mentorship experience, I learned that encouraging others to succeed situates oneself on the path to success.

For the group of classmates, there was little separation between our academic pursuits and our personal lives. Both inside and outside of class, we reflected on personal experiences and shared them with each other. Then we cogitated on each other's perspectives, thereby embellishing our learning and strengthening our ability to consider multiple worldviews. As a part of this learning, we graduated from a $\mathrm{PhD}$ program with a more encompassing perspective about life. In a similar context, Freire (1970) stated, "Liberation is a praxis; the action and reflection of men [and women] upon their world in order to transform it" (p. 66).

\section{Discussion: Key Aspects of Peer Mentorship}

Our peer mentorship involved aspects of trust and features of friendship; however, our peer mentorship experience was more than a group of friends getting together before, during, and after class. In fact, the formal birthplace of our peer mentorship had nothing to do with trust. It emerged from a group of professors who made the decision to accept a cohort of PhD students into a graduate program. Moreover, peer mentorship flourished due to the boundaries within the program. For example, each student in the newly formed cohort took four initial graduate courses together on a full-time basis while maintain- 
ing no lower than a 70\% average. Peer mentorship was also influenced by the proximity of shared office space for each student in our cohort. In this way, peer mentorship was initially structured within the physical, logistical, and institutional features of the PhD program. Then it was enacted through the social interactions that transpired due to the academic and pedagogical parameters of the program and through a national and international group of students who were enrolled in the cohort.

Another key characteristic of our peer mentorship experience was that each student had the freedom to mentor and be mentored by their peers in ways that addressed differentiated needs and abilities. "Mentoring is best when it is free of pressure, and when it feels reciprocal” (Cullingford, 2006, p. 9). For us, such a dynamic process was in a continuous state of flux, because our roles as mentor and mentee proved to be interchangeable and flexible. Often times, the role of mentor and mentee became blurred, and, at any time, a peer could assume the role of mentor, mentee, or both. These symbiotic relationships were not coerced into existence by pre-determined peer mentorship responsibilities; rather, our peer mentorship experience was organic, in that each of us gave and grew according to our abilities, skills, and life situations.

It was both the dichotomous freedom and the structure of the program that created an ideal environment where peer mentorship thrived. Peer mentorship emerged from the organic needs, the diverse potential, and individual strengths of our student group as well as from the administrative scaffolding of the $\mathrm{PhD}$ program. In turn, these characteristics were responsible for the creation of a microcosm of transformational learning for our student cohort.

\section{Implications of Peer Mentorship}

There are implications attached to our peer mentorship and transformational learning experiences. In striving to promote peer mentorship and transformational learning, educators need to view both these processes as dynamic, flexible, student-focused learning events. Postsecondary instructors need to plan courses and facilitate classroom activities where students are encouraged to voice their individualized and collective lived experiences. To achieve this type of learning, leaders in postsecondary institutes should consider supporting instructors by promoting teacher-student academic retreats, supplying graduate student office space that enables regular peer interaction, and supplying professional development on the topic of peer mentorship.

We believe peer mentorship is an under-utilized resource with great capacity to foster human and social capital within and between cohorts of graduate students. In enabling peer mentorship to thrive, postsecondary institutions can potentially receive high academic returns on a limited investment of finances, a point that is especially relevant during modern times where financial restraints and budget cuts are common. As illustrated in our stories, many of the fundamental aspects of peer mentorship cost little to nothing. These free or virtually free aspects involve developing transformative learning opportunities and were enabled through simple things such as instructors promoting group projects and peers and professors enjoying regular coffee talks. In turn, shared experiences fostered a caring, trustful learning environment, a gift that costs nothing.

Potter (2006) noted that only 55\% of Canadian students pursuing a $\mathrm{PhD}$ in the social sciences actually finish their program; these statistics are similar in the United States, 
where about half of the students who begin a doctoral program complete their degree (Bair \& Haworth, 2004; Gardner, 2008). Efforts to improve $\mathrm{PhD}$ attrition rates generally focus on financial support, academic preparation, professional development, and trusting relationships (Bair \& Haworth, 2004). We articulated how most of these supports were naturally provided through the formal and informal experiences of peer mentorship. As mentioned in our stories, the cultivation of peer mentorship within our $\mathrm{PhD}$ programs was the reason one of our cohort members decided to persevere and remain in the program. In turn, we argue that peer mentorship is a potential vehicle to reduce graduate student attrition rates.

The current migration of foreign students into North American and European higher education institutions continues a decades-long trend. In the context of this study, the 10 students of our $\mathrm{PhD}$ cohort represented five countries from four continents; such a large representation of international graduate students is not uncommon in postsecondary settings. Rose (2005) indicated that international students often find peer mentoring to be invaluable, because such social interactions are successful coping mechanisms for the cultural challenges many students experience when attending school in another country. In our experience, peer mentorship was a source of accommodation and acculturation for both the local (national) and international students within our cohort, because both local and international students gained first-hand experience of different languages, cultural propensities, and worldviews. For both local and international students who experience peer mentorship, there is great potential to understand world issues through the firsthand interaction with peers. Put another way, having an international friend is a form of transformational learning, because friendship requires the ability to see issues from another person's point of view. In addition, international students who return to their home countries take with them the lived experience, the skills, and potentially some Canadian values they have acquired through their peer mentorship experiences.

In closing, we thank our cohort members for the invaluable gifts they gave us. Many years have passed since the first day we sat together as new $\mathrm{PhD}$ students. For a finite time, we shared intellectual, emotional, and ethical space; a memorable experience that was seminal in creating an ideal condition for learning. Although most of us are now separated by vast distances, we still carry the learning we created for and with each other, and we confidently believe that this learning will continue to positively affect us in our future.

\section{References}

Allen, T. C., \& Eby, L. T. (2007). Overview and introduction. In T. C. Allen \& L. T. Eby (Eds.), The Blackwell handbook of mentoring: A multiple perspectives approach (pp. 3-6). Malden, MA: Blackwell.

Auger, W. F., \& Rich, S. J. (with Langford, H.). (2007). Curriculum theory and methods: Perspectives on learning and teaching. Mississauga, ON: John Wiley \& Sons Canada.

Badger, K. (2010). Peer teaching and review: A model for writing development and knowledge synthesis. Social Work Education, 29(1), 6-17. 
Bair, C., \& Haworth, J. G. (2004). Research on doctoral student attrition and retention: A meta synthesis. In J. C. Smart (Ed.), Higher education: Handbook of theory and research XIX (pp. 481-534). New York, NY: Agathon.

Black, J. (2010). Strategic enrolment issues facing higher education leaders. In J. Black (Ed.), Strategic enrollment intelligence (pp. 14-26). Toronto, ON: Academica Group.

Brockett, R. G., \& Hiemstra, R. (1991). Self-direction in adult learning: Perspectives on theory, research, and practice. New York, NY: Routledge.

Carter, T. J. (2002). The importance of talk to midcareer women's development: A collaborative inquiry. Journal of Business Communication, 39(1), 55-91. doi:10.1177/002194360203900104

Chase, S. E. (2005). Narrative inquiry: Multiple lenses, approaches, voices. In N. K. Denzin \& Y. S. Lincoln (Eds.), The Sage handbook of qualitative research (3rd ed., pp. 651-679). Thousand Oaks, CA: Sage.

Ciuffetelli Parker, D., Pushor, D., \& Kitchen, J. (2011). Narrative inquiry, curriculum making, and teacher education. In J. Kitchen, D. Ciuffetelli Parker, \& D. Pushor (Eds.), Narrative inquiries into curriculum making in teacher education (pp. 3-18). Bingley, England: Emerald Group.

Clandinin, D. J. (2006). Handbook of narrative inquiry: Mapping a methodology. Thousand Oaks, CA: Sage.

Clandinin, D. J., \& Connelly, F. M. (1998). Asking questions about telling stories. In C. Kridel (Ed.), Writing educational biography: Exploration in qualitative research (pp. 245-253). New York, NY: Garland.

Clandinin, D. J., \& Connelly, F. M. (2004). Knowledge, narrative, and self-study. In J. Loughran, M. Hamilton, V. LaBoskey, \& T. Russell (Eds.), International handbook of self-study of teaching and teacher education practices (pp. 575-600). Boston, MA: Kluwer Academic.

Clark, M. C. (1993, Spring). Transformational learning. New Directions for Adult and Continuing Education, 57, 47-56. doi:10.1002/ace.36719935707

Connelly, F. M., \& Clandinin, D. J. (1988). Teachers as curriculum planners: Narratives of experience. New York, NY: Teachers College Press.

Craig, C. J. (2011). Narrative inquiry in teaching and teacher education. In J. Kitchen, D. Ciuffetelli Parker, \& D. Pushor (Eds.), Narrative inquiry into curriculum making in teacher education (pp. 19-42). Bingley, England: Emerald Group.

Cullingford, C. (2006). Mentoring as myth and reality: Evidence and ambiguity. In C. Cullingford (Ed.), Mentoring in education: An international perspective (pp. 1-10). Aldershot, England: Ashgate.

Dewey, J. (1938). Experience and education. New York, NY: Macmillan.

Freire, P. (1970). Pedagogy of the oppressed. New York, NY: The Seabury Press.

Freire, P. (2004a). Pedagogy of hope: Reliving pedagogy of the oppressed (R. R. Barr, Trans.). London, England: Continuum International. 
Freire, P. (2004b). Pedagogy of indignation. Boulder, CO: Paradigm.

Fresko, B., \& Wertheim, C. (2003). Building cultures of caring and empowerment for Israel's at-risk youth. In F. L. Kochan \& J. T. Pascarelli (Eds.), Global perspectives on mentoring: Transforming contexts, communities, and cultures (pp. 23-38). Greenwich, CT: Information Age.

Gardner, S. (2008). "What's too much and what's too little?” The process of becoming an independent researcher in doctoral education. Journal of Higher Education, 79(3), 326-350.

Gill, S., \& Goodson, I. (2011). Life history and narrative methods. In B. Somekh \& C. Lewin (Eds.), Theory and methods in social research (2nd ed., pp. 157-165). Los Angeles, CA: Sage.

Giroux, H. A. (1981). Ideology culture \& the process of schooling. London, England: Temple University Press.

Giroux, H. A. (1983). Teacher education and the ideology of social control. In H. A. Giroux \& D. Purpel (Eds.), The hidden curriculum and moral education: Deception or discovery (pp. 404-425). Berkeley, CA: McCutchan.

Giroux, H. A. (1996). Is there place for cultural studies in Colleges of Education? In H. A. Giroux, C. Lankshear, P. McLaren, \& M. Peters (Eds.), Counter narratives: Cultural studies and critical pedagogies in postmodern spaces (pp. 41-58). New York, NY: Routledge.

Grant-Vallone, E. J., \& Ensher, E. (2000). Effects of peer mentoring on types of mentor support, program satisfaction, and graduate student success: A dyadic perspective. Journal of College Student Development, 41(6), 637-642.

Heirdsfield, A., Walker, S., Walsh, K., \& Wilss, L. (2008). Peer mentoring for firstyear teacher education students: The mentor's experience. Mentoring and Tutoring: Partnerships in Learning, 16(2), 109-124.

Huizing, R. L. (2012). Mentoring together: A literature review of group mentoring. Mentoring \& Tutoring: Partnerships in Learning, 2O(1), 27-55.

Kincaid, N. M., \& Sotiriou, P. (2004). Service-learning at an urban two-year college. Teaching English in the Two-Year College, 31(30), 248-259.

King, K. P. (2005). Bringing transformative learning to life. Marlabar, FL: Krieger.

Le Cornu, R. (2005). Peer mentoring: Engaging pre-service teachers in mentoring one another. Mentoring and Tutoring, 13(3), 355-366.

Merriam, S. B., Caffarella, R. S., \& Baumgartner, L. M. (2007). Learning in adulthood: A comprehensive guide (3rd ed.). San Francisco, CA: Jossey-Bass.

Mezirow, J. (1981). A critical theory of adult learning and education. Adult Education, 32(1), 3-25. doi:10.1177/074171368103200101

Mezirow, J. (1991). Transformational dimensions of adult learning. San Francisco, CA: Jossey-Bass. 
Mezirow, J. (1997, Summer). Transformative learning: Theory to practice. New Directions for Adult and Continuing Education, 74, 5-12. doi:10.1002/ace.7401

Mezirow, J. (2000). Learning as transformation: Critical perspectives on a theory in progress. San Francisco, CA: Jossey-Bass.

Mezirow, J., Taylor, E. W., \& Associates. (2009). Transformative learning in practice: Insights from community, workplace, and higher education. San Francisco, CA: JosseyBass.

Potter, A. (2006, June 26). But what do you want a Ph.D. for? MacLean's. Retrieved from http://www.macleans.ca/article.jsp?content=20060626_129724_129724

Rose, G. (2005). Group differences in graduate students' concepts of ideal mentor. Research in Higher Education, 46(1), 53-80.

Schwandt, T. A. (2007). First words. In B. Somekh \& T. A. Schwandt (Eds.), Knowledge production: Research work in interesting times (pp. 1-5). London, England: Routledge Taylor \& Francis Group.

Skelton, A. (2005). Understanding teacher excellence in higher education: Towards a critical approach. London, England: Routledge.

Taylor, E. W. (1998). Transformative learning: A critical review. ERIC Clearinghouse on Adult, Career, and Vocational Education. (Information Series No. 374)

Taylor, E. W. (2007). An update of transformative learning theory: A critical review of the empirical research (1999-2005). International Journal of Lifelong Education, 26(1), 173-191.

Taylor, E. W. (2009). Fostering transformative learning. In J. Mezirow \& E. W. Taylor (with Associates), Transformative learning in practice: Insights from community, workplace, and higher education (pp. 3-17). San Francisco, CA: Jossey-Bass.

Trorey, G., \& Blamires, C. (2006). Mentoring new academic staff in higher education. In C. Cullingford (Ed.), Mentoring in education: An international perspective (pp. 167182). Aldershot, England: Ashgate.

\section{Contact Information}

Jane P. Preston

Faculty of Education

University of Prince Edward Island

jpreston@upei.ca

Jane Preston is an assistant professor in the Faculty of Education, University of Prince Edward Island whose educational outlook is based on experience gained while teaching kindergarten to Grade 12 classes in Canada, Taiwan, Egypt, and Kuwait. Her research interests include leadership issues, parent/community involvement in schools, rural education, and Aboriginal/Indigenous issues. 
Marcella Ogenchuk RN, PhD has practised nursing in a variety of settings including acute care and the community for the past 25 years. As an assistant professor in the University of Saskatchewan College of Nursing, she is involved in teaching nursing students in the area of pediatrics. Her teaching and passion focus on children and youth wellness and she uses an interdisciplinary approach. Her research area investigates preventing the use of alcohol by youths and the harm related to its use of alcohol by them.

Ordained to the Catholic priesthood 1988, Joseph Nsiah has served as assistant pastor and pastor in parishes in Ghana and in Saskatchewan. At various times in his career, he has held the positions of chaplain, senior housemaster, and assistant principal with special duties in a Catholic boarding high school in Ghana. A graduate from the University of Cape Coast in Ghana with a BA Arts degree in French, he holds both a doctoral and master's degrees in educational administration from the University of Saskatchewan. He is currently Vicar General of the Catholic Diocese, Jasikan, Ghana. 